\title{
REVISTA DE HISTORIA MODERNA
}

ANALES DE LA UNIVERSIDAD DE ALICANTE N 20 - 2002

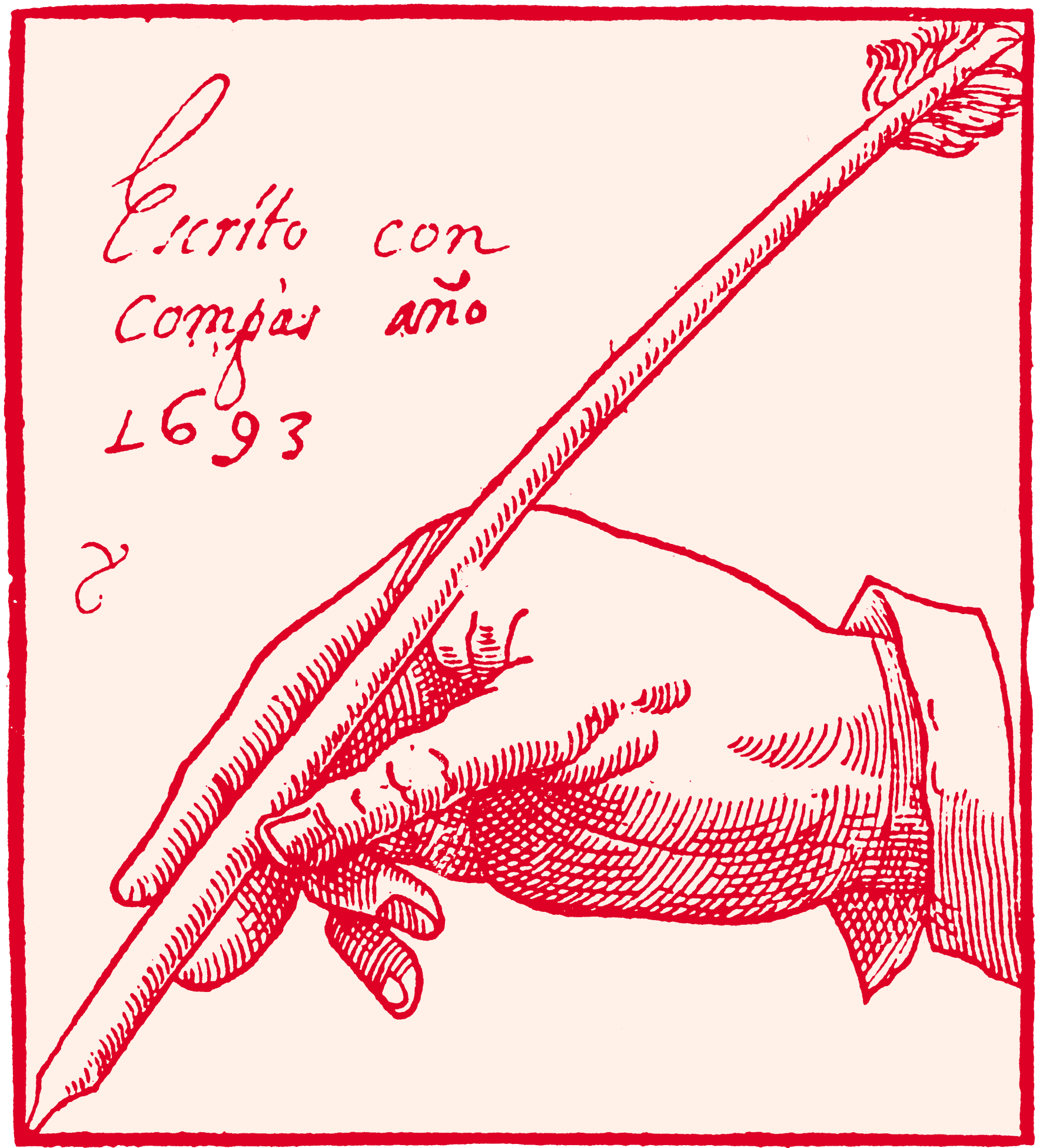

ENSEÑANZA Y VIDA ACADÉMICA EN LA ESPAÑA MODERNA 


\section{Preimpresión

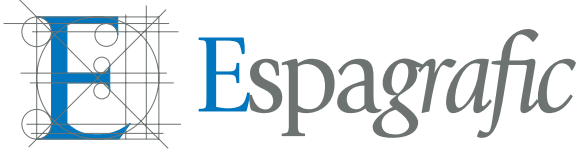

Impresión: INGRA Impresores

ISSN: 0212-5862

Depósito Legal: A-81-1982

Reservados todos los derechos. No se permite reproducir, almacenar en sistemas de recuperación de la información ni transmitir alguna parte de esta publicación, cualquiera que sea el medio empleado -electrónico, mecánico, fotocopia, grabación, etc.-, sin el permiso previo de los titulares de los derechos de la propiedad intelectual.

\section{Estos créditos pertenecen a la edición impresa de la obra.}

\section{Edición electrónica:}

E Espagrafic 
Revista de Historia Moderna

Anales de la Universidad de Alicante ํㅜ 20 - 2002

\title{
Enseñanza y vida académica en la España Moderna
}

\author{
Enrique Giménez López \\ La enseñanza en el seminario de nobles \\ educandos tras la expulsión de los jesuitas. \\ Un capítulo de la lucha por el control \\ de la enseñanza en Valencia
}




\section{Índice}

\section{Portada}

\section{Créditos}

Enrique Giménez López

La enseñanza en el seminario de nobles educandos tras la expulsión de los jesuitas. Un capítulo de la lucha por el control de la enseñanza en Valencia

Resumen

Abstract

Notas. 


\section{La enseñanza en el seminario de nobles educandos tras la expulsión de los jesuitas. Un capítulo de la lucha por el control de la enseñanza en valencia}

\section{Resumen}

Con la expulsión de los jesuitas en 1767 se inició una pugna por el control de la enseñanza en la ciudad de Valencia entre dos grupos encabezados por el erudito Gregorio Mayans y el preceptor de los Infantes Francisco Pérez Bayer. Al mantenerse la enseñanza de la Latinidad en el edificio del antiguo Colegio de los Jesuitas de San Pablo, convertido en Seminario de Nobles, y separada de la Universidad hasta 1774, el tipo de docencia que se impartía en ese centro fue objeto de fuertes controversias, en las que intervino el Consejo de Castilla.

\section{Abstract}

When the jesuits were expelled in 1767, the struggle for the control of teaching in the city of Valencia began. The main combatants were the scholar Gregorio Mayens and Francisco Pérez Mayer, 
Latin tutor to the King's children. As the Latin cultural tradition was maintained at the former Jesuit School, now the Noble's Seminary, separated from the University until 1774, the type of teaching imparted at this centre became the object of violent controversy, in which the Council of Castile intervened.

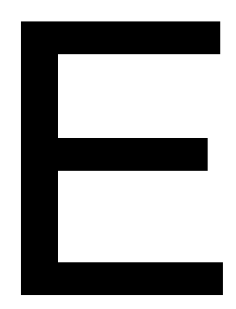

26 de diciembre de 1772 Gregorio Mayans escribía a su amigo, el bibliotecario Martínez Pingarrón, dándole noticia de un cambio que se había producido en la dirección del Seminario de Nobles de Valencia, antiguo Colegio de San Pablo de los jesuitas, y que le afectaba de manera muy directa por suponer un amargo eslabón más en sus intentos por mejorar -y controlar- la enseñanza de las humanidades: «El ex-congregante Moricó (nota 1) ha sido elegido prefecto de este seminario de Nobles, que ha regentado el canónigo Segarra, que ha sido el que ha mantenido la ignorancia de los maestros, la qual ha hecho desertar a los discípulos i éstos han ido a los esculapios; i todo ello por contradecir i impedir la introducción de mi Gramática en gravísimo daño público irreparable, injusto, enormíssimo; i ahora sabemos qué Gramática se enseñará (nota 2), aunque ha avido tres órdenes generales del Consejo i un privilegio real en favor de la mía. Créame Vm. que he tenido mucho que 
sentir i que dissimulo por no poner las cosas en peor estado. Hágase lo que Dios quiera i súfrase todo lo que permite» (nota 3). Las esperanzas puestas por el erudito de Oliva en que, tras la expulsión de la Compañía de Jesús, las letras volverían al esplendor perdido y que las costumbres mejorarían, siendo él el elegido para dirigir tan compleja operación, recibieron un serio revés con lo sucedido en el Seminario de Nobles de Valencia entre 1767 y 1772, precisamente un centro donde, supuestamente, debía ponerse en marcha la renovación esperada y que, por el contrario, derivó en un ejemplo de las luchas por el poder educativo desatadas tras la desaparición de los jesuitas.

El mismo día en que los regulares de la Compañía eran desalojados de su Colegio de San Pablo de Valencia, el corregidor-intendente, Andrés Gómez de la Vega, decidió que la enseñanza que impartían las cátedras de Gramática Latina que la Compañía de Jesús poseía en aquel centro, separadas de la Universidad en 1720, no se interrumpiera (nota 4). Con esa finalidad encomendó la dirección del centro, ahora denominado Seminario de Nobles educandos, a Joaquín Segarra, familiar (nota 5) del preceptor de los Infantes Reales Francisco Pérez Bayer y castellonense como éste (nota 6), y amigo íntimo de Vicente Blasco y García, también preceptor 
de Infantes Reales (nota 7). Mayans le informaba de esta novedad a su corresponsal, el bibliotecario Martínez Pingarrón: «En el seminario de Valencia se ha puesto por prefecto de los estudiantes al Dr. Joaquín Segarra, que lo es del Colegio del Patriarca» (nota 8).

El mantenimiento de las Aulas de Gramática desgajadas de la Universidad en el antiguo Colegio jesuita, suponía la pervivencia de un problema que se dilataba desde 1720. Mayans había defendido, inmediatamente después de la expulsión, que en los Colegios de la Compañía ubicados en ciudades que fueran sede universitaria cesara toda actividad docente de las cátedras de Gramática, y que esta enseñanza correspondiera en exclusiva a las Universidades: «que alguna casa capaz de las de la Compañía se destine en cada ciudad, en donde ai Universidad, a un pupilage honrado i bien educado en donde no aya estudios, sino recogimiento i educación christianamente necesaria para los estudiantes» (nota 9). Pero en torno al problema de que la enseñanza del latín y el griego de mantuviera separada de la Universidad, se dilucidaba una pugna por el control de los estudios en Valencia que, siendo más amplia, vamos a circunscribirla en este trabajo al ámbito del Seminario de Nobles educandos. 
Gracias al apoyo de Pérez Bayer, Blasco, Roda y el P. Eleta, confesor del Rey, Segarra logró en noviembre de 1767 un canonicato en detrimento de Juan Antonio Mayans, pese a figurar aquél en último lugar de la terna (nota 10), logrado ser rector del Estudi General valenciano en 1778 en sustitución del hermano menor de D. Gregorio, que lo fue durante el trienio comprendido entre 1775 y dicho año (nota 11). Segarra era, a la vez, miembro muy destacado de la influyente «facción bayeriana» o «pereziana» (nota 12) y de la escuela tomista, unidas temporalmente en su afán de controlar la educación en Valencia, pues a Pérez Bayer le debía Segarra la dirección del Seminario de Nobles, el canonicato (nota 13) $y$, posteriormente, el rectorado. En el otro lado Gregorio Mayans se postulaba para dirigir la reforma de los estudios en Valencia (nota 14), para lo que no cesaba de calificar de ignorantes y ambiciosos a todos sus opositores, y situar en un estratégico canonicato a su hermano Juan Antonio, como plataforma para lograr en su momento el rectorado de la Universidad, ya que éste debía ser ocupado siempre por un canónigo o, en su defecto, tratar de compensar aquellos otros canónigos de la catedral nombrados por el rey a recomendación de Pérez Bayer.

\section{ÍNDICE}


El nuevo director del Seminario, de acuerdo con el corregidorintendente, procedió a nombrar a los docentes que debían ocupar de inmediato, aunque de forma interina, el hueco dejado por los jesuitas. Como Maestros de Latinidad se escogió a los Drs. Luis Martínez y Clemente Benedicto, sacerdotes seculares que durante algunos años habían sido preceptores de Latinidad en las aulas que tenía abiertas el Cabildo de la Iglesia Metropolitana de Valencia. Un día después, el 5 de abril, fue encargado de las clases de Latinidad el sacerdote Vicente Griñó, mientras que el corregidor elegía para la impartición de la Prosodia y la Retórica al presbítero y doctor José Plana. Posteriormente el cuerpo docente se completó con un Maestro de Primeras Letras, el presbítero José Martí, y con Jaime Beltrán y Vera, Maestro de Aritmética y Primeras Letras.

Desde finales de 1767, los esfuerzos de Mayans se dirigieron a conseguir la dirección de los estudios en Valencia utilizando la vía del consejero de Castilla Miguel María Nava y del fiscal Campomanes, y en un grado menor la del Presidente del Consejo el Conde de Aranda. Era misión casi imposible, pues esa labor debía ejecutarla un Consejero de Castilla, pero Mayans optó por presentarse como el hombre imprescindible denunciando, en los tonos más sombrios posibles, el estado 
de la enseñanza en Valencia, con la más contundente descalificación de aquellos a quienes consideraba culpables y que, a fin de cuentas, eran los que pugnaban con él por el control de las letras.

El ejemplo del Seminario de Nobles de Valencia fue piedra de toque reiteradamente utilizado por Mayans en esas descalificaciones. En agosto de 1768 se dirigía a Campomanes para recomendar una vez más a su hermano para el canonicato dejado vacante por fallecimiento del canónigo Mascarell y, al tiempo, pedir una acción enérgica del Consejo, con él mismo como ejecutor, para poner coto al «cuerpo de ignorantes, i peor que ignorantes, que está enseñoreado de la Escuela $i$ sostiene la barbarie. I en el canónigo Segarra se ve un egemplo público del daño que su prefectura ha causado en el Seminario de San Pablo, sin averse experimentado mejoría alguna en la enseñanza de la lengua latina». Para ello era necesaria una acción decidida, para la que el propio Mayans se consideraba el más adecuado: «Por lo que se hace necesario que V.S. IIma. aplique su brazo fuerte para que se impida la continuación de estos desórdenes; y para conseguirlo es menester que aquí aya hombres instruidos en las cosas de este reino, buenos i fuertes» (nota 15). Esta denuncia y disposición las reiteró en su correspondencia, en términos simi- 
lares a los ya reseñados, desde el otoño de 1768 hasta la primavera de 1771. El 22 de mayo de aquel año el Claustro Mayor de la Universidad de Valencia, dominado por los tomistas, votó diferir el cumplimiento del decreto del Consejo que imponía la Gramática mayansiana en la enseñanza del latín, con intervención activa del director del Seminario de Nobles anunciando que tampoco se utilizaría en el centro por él regentado. El primero de junio, el mismo día que Mayans informaba con toda la indignación de que era capaz a Campomanes la decisión del Claustro, también pasaba a denunciar, con detalle, la situación docente del Seminario en términos muy similares a los que posteriormente utilizará el Dr. Plana ante el Consejo: «son tan ignorantes [los maestros del Seminario] que ni aún son capaces de enseñar medianamente la gramática común, como maestros que eligió el canónigo Joaquín Segarra, sin aver precedido exámenes ni concursos. De los quales únicamente el maestro de rethórica que es el Dr. La Plana, no puesto por el canónigo Segarra, es el que ha sacado algunos discípulos de provecho» (nota 16). Es probable que Plana, amigo de D. Gregorio, iniciara sus denuncias ante el Consejo en noviembre de 1771 siguiendo instrucciones de Mayans, y como una fase más de su plan de batalla con la facción «bayerista», pese a que en febrero de 
1772 Mayans negara en carta a Aranda haber empujado a aquél «para que formasse dos memoriales en que trata de la conducta que ha tenido en aquel Seminario el canónigo D. Joaquín Segarra» ni contra Bayer y Blasco, «siendo assí que no he sabido lo contenido en los memoriales del Dr. Plana hasta después de averlos él embiado, quando ya corrían por aquí muchas copias» (nota 17).

Lo cierto es que el 12 de noviembre de 1771, el profesor de Retórica José Plana acudía al Consejo de Castilla para denunciar, en términos durísimos, la situación del Seminario. Los Maestros que Segarra había nombrado para impartir la enseñanza de primeras letras y latinidad eran de una manifiesta ignorancia, y con su nefasta labor docente contribuían a la ruina de las humanidades en lugar de conseguir su reforma, tal y como se había previsto tras la expulsión de los ignacianos. Plana acudía al Consejo después de comprobar que sus intentos de poner en conocimiento de la Universidad la situación del Seminario habían sido impedidos por el obispo auxiliar, el agustino Rafael Lasala (nota 18), en su condición de canciller de la Universidad, que con la ayuda en la Corte de Pérez Bayer y Blasco, bloqueaban cualquier denuncia contra lo que Plana calificaba de «coligación de Maestros capitaneada de Segarra y favorecida de Pérez Bayer» (nota 19). El 
denunciante solicitaba que el Consejo tomara en sus manos la reforma del Seminario, sustituyendo al canónigo Segarra, nombrando otro director o una junta, presidida por un Oidor de la Audiencia, que investigara el proceder de Segarra en los años transcurridos desde 1767, especialmente su reiterada negativa a cumplir los Decretos del propio Consejo para que su utilizara como texto la Gramática latina de Mayans (nota 20), de lo que había alardeado públicamente (nota 21), incluso en el Claustro Mayor universitario donde «tuvo el atrevimiento para decir que, aunque el Consejo se lo mandasse, no obedecería» (nota 22).

No hay duda que las opiniones vertidas en los memoriales por Plana son coincidentes con las de Mayans, expresadas al Presidente del Consejo en octubre de 1770 cuando advirtió de los peligros que supondría que la dirección de los estudios valencianos recayera en el obispo Lasala, alter ego del canónigo Segarra, y piezas ambos de las ambiciones de Bayer: «Creo que estamos en el estado crítico de la perdición o restauración de esta Universidad de Valencia. La facción Pereziana está peleando con el mayor encono para que este obispo auxiliar [Lasala] sea director de los estudios; porque, si lo fuere, conseguirá que sea el mantenedor del sistema de 
la ignorancia, siendo el mandarín de esta ciudad en lo tocante a las letras» (nota 23).

Plana, al igual que Mayans, demandaba que unos nuevos Maestros, previo examen, sustituyesen en las Aulas de Gramática a las nulidades colocadas por Segarra. Estos nuevos Maestros debían ser «hábiles, bien acondicionados de edad y salud competente para poder servir ahora, sean eclesiásticos o seculares que aspiren a dicho estado, siendo de buena vida y loables costumbres», y en su elección no debían participar ni el obispo Lasala ni el corregidor-intendente, por ser el primero íntimo "y casi dependiente» del canónigo Segarra, y el segundo "estar poseído» por éste hasta el punto «que le hace representar ciegamente al Supremo Consejo cuanto conviene a sus siniestras ideas, sirviéndole como de un obediente amanuense» (nota 24).

El temor de Plana a que Pérez Bayer y Blasco impidieran que su representación de finales de 1771 llegara al Consejo, le condujo a remitir un escrito al fiscal Rodríguez de Campomanes, apoyo y confidente de Mayans en este asunto, fechado el 18 de enero de 1772 (nota 25). En la descalificación que hacía de Segarra le comparaba con los jesuitas expulsos, pues el canónigo, a su entender, poseía los rasgos que definían genéricamente a los miembros de la Compañía 
por sus estratagemas, violencias y audacia. Al igual que los jesuitas, Segarra había alcanzado crédito de hombre sabio en el terreno de la Teología (nota 26) con mañas y artificios, siendo como era un ignorante, acusación esta de apego a los projesuitas que también había efectuado reiteradamente Mayans (nota 27).

Esa ignorancia distintiva del talante de Segarra había sido decisiva en la selección del profesorado del Seminario, cuyas características describía Plana con tintes muy negros, pues «ninguno de los que están allí entienden el latín del autor más fácil de latinidad», utilizando barbarismos sin tasa alguna. El Maestro de Primeras Letras tenía dificultades para leer textos castellanos, y el de Latinidad era incapaz de enseñar los rudimentos de la gramática. De ambos, Plana tenía dudas muy serias sobre su equilibrio mental: el primero «está maniático», y había decidido no hablar al poco tiempo de iniciar su docencia en el Seminario, mientras que el segundo «en la trivial conversación habla desconciertos, y con dificultad puede capacitarse de lo que le dicen» (nota 28). Tampoco era favorable el juicio de Plana sobre sus compañeros del segundo y tercer curso de Latinidad. El primero era hombre de conocimientos muy limitados y su salud estaba tan deteriorada que estaba incapacitado para la docencia. El segundo, Vicente 
Griñó, tenía más de 62 años de edad, era cojo, y pasaba su tiempo en el aula "en cuentos y fruslerías» en lugar de traducir a Ovidio y las Epístolas de Cicerón. Griñó procuraba disimular su ignorancia practicando una violencia brutal con los alumnos, a quienes arrojaba objetos diversos, les asía frecuentemente de los cabellos y orejas, y les daba zurriagazos y patadas «corrigiendo con descompasados gritos y furores, con lo que más confunde que instruye». El resultado era que los alumnos pasaban a Plana ignorándolo casi todo, obligándole a enseñarles la sintaxis cuando estaba encargado en su docencia de impartir prosodia y retórica.

El descrédito del Seminario en Valencia era grande. El número de estudiantes se había ido reduciendo de año en año, en provecho de los escolapios, cuyo derecho de enseñar gramática en Valencia fue reconocido en 1760, abriéndose el Seminario Andresiano en 1763 bajo el auspicio del arzobispo Andrés Mayoral (nota 29), protector, a su vez, de Lasala: el Seminario de Nobles había pasado de 300 alumnos a sólo 70 en la enseñanza de las primeras letras; las Escuelas de Gramática habían perdido las tres cuartas partes del alumnado al pasar de 400 alumnos a poco más de 100, y de 70 Colegiales Seminaristas tan sólo quedaban 12.

\section{ÍNDICE}


La ruptura entre Plana y Segarra se había producido con la redacción del Plan de estudios del Seminario, encargado por el Consejo al rector y al corregidor-intendente el 31 de diciembre de 1770, y que retardaba el traslado de las Aulas de Gramática a la Universidad. El Plan debía atender a tres aspectos: la enseñanza de colegiales y seminaristas, con expresión de materias, clases, autores, método y distribución de horas; la dirección espiritual de los alumnos y la cantidad en metálico que debían aportar los pensionistas; y la administración de las rentas del centro, con los sueldos de su personal docente, es decir, Maestros de Primeras Letras, Latinidad y Retórica. Había dificultades serias para dotar al centro de una calidad adecuada: no contaba con libros suficientes, pues la librería de los jesuitas había pasado a engrosar la biblioteca arzobispal, la renta era muy limitada, con sólo 2.400 libras anuales, y la configuración del edificio, si bien de gran amplitud y cuadrangular, tenía las habitaciones de los Maestros situadas en zonas del edificio con dificultad de acceso rápido a las estancias de los seminaristas internos, hijos de familias de abolengo nobiliario. Sólo se realizarían obras de acondicionamiento a partir de 1785 cuando gracias al entonces su director, el Dr. Joaquín Mas, catedrático de Teología y también muy próximo al grupo de Pérez Bayer y 
Blasco (nota 30), obtuvo de Carlos III la Real Orden de 10 de diciembre de 1784 para que la Dirección General de Temporalidades librase 120.000 rls. que el Seminario necesitaba (nota 31) de los fondos procedentes de las temporalidades de los jesuitas de Valencia (nota 32).

El 3 de octubre de 1771 Segarra y el corregidor Andrés Gómez de la Vega reunieron al profesorado para presentarles el Plan ya elaborado. Plana se manifestó contrario a que los Maestros que, de forma interina, se ocupaban de la docencia se convirtieran en fijos, pues iba en contra del sentimiento reformista de que no enseñaran gramática los que no hubiesen logrado plaza por oposición, previa publicidad (nota 33). Para Plana los Maestros del centro eran «Maestros fingidos, y que sobre esta infelicidad los colegiales y estudiantes han de ser el blanco de sus iras y furores, efectos irreparables de sus achaques, vejez y genios ridículos» (nota 34). Ya finalizada la junta, el cruce de palabras entre Plana y Segarra alcanzó un alto grado de violencia. El primero acusó al canónigo de ser el responsable del deterioro de la enseñanza y que estaba acabando con el Seminario de Nobles al pretender «encastillar» a Maestros ignorantes, que harían la guerra, una vez fijos en sus puestos, a cualquiera que tuviera conocimiento de las lenguas clásicas, como él mismo. Además, no 
se había provisto la cátedra de Lengua Griega, pese a percibirse de la ciudad la dotación económica correspondiente a esa plaza. Segarra lo amenazó «que le había de sepultar», y le anunció que daría parte al obispo. El prelado, de común acuerdo con Segarra y el corregidor, y contando con las declaraciones de los Maestros que habían sido testigos del incidente, dio orden de detención contra Plana, que pasó al convento de Carmelitas Descalzos de Valencia con el cargo de haber injuriado verbalmente al rector y haber sido irrespetuoso con el corregidor.

Sólo después de 25 días, tras declarar el detenido que deseaba presentar excusas a los ofendidos y pagar las costas, fue puesto en libertad, si bien con el apercibimiento de que «fuera a dar satisfacción a los mencionados» (nota 35). No pudo regresar de inmediato a la docencia, pues el corregidor le obligó a presentarse ante él cada tres días para acreditar su obediencia, y sólo después de transcurridos otros 24 días el corregidor le permitió regresar al aula, donde sólo quedaba un estudiante de quienes fueran sus pupilos. Según Plana, el haberlo tenido apartado casi dos meses de la enseñanza tenía como propósito dejarle sin alumnos y no poder ser comparados sus métodos con los de los restantes Maestros que, en su opinión, «afianzan su saber en que nadie sepa, y vién- 
dose descubiertos apartan por sí (...) a todos los que pueden notarles su notoria ignorancia» (nota 36), y a quienes, como él, utilizaban la persuasión como método de aprendizaje y no el castigo.

Las denuncias del Dr. Plana al Consejo dieron como resultado la solicitud de un informe a la Universidad. Dos Pabordes catedráticos designados por el Claustro, Joaquín Antonio Gombau, catedrático de víspera de Cánones, y Fray Vicente Capera, catedrático de prima de Matemáticas, fueron los encargados de elaborarlo (nota 37). La presencia de Capera debió ser determinante en el sesgo que tomó el informe, nada favorable a Plana. Capera era un religioso de la Orden de Montesa, a la que también pertenecía Vicente Blasco, que seguía explicando matemáticas por los seis primeros libros de Euclides, y muy próximo al obispo Lasala, que también había sido catedrático de Matemáticas entre 1745 y 1768 y colaborador de Capera en tareas arquitectónicas (nota 38). Además, sus relaciones con Mayans y su entorno eran muy malas, ya que D. Gregorio se había manifestado partidario de su contrincante en la oposición a la cátedra, Antonio Capdevila (nota 39), y había juzgado muy negativamente la elección de Capera con quien, en su opinión, era imposible aprender matemáticas en Valencia (nota 40). El poder de 
Segarra y del obispo Lasala en la Universidad, con el apoyo del corregidor en la ciudad y de Pérez Bayer y Blasco en la Corte, dio como resultado un informe que rebatía, punto por punto, las denuncias de Plana y representaba un importante revés para Mayans.

El 21 de febrero de 1772 llegaba el informe de la Universidad a manos del Consejo. En él se negaba que los estudios del Seminario de Nobles se hallasen en decadencia, y si los alumnos tenían un «corto adelantamiento», no era éste inferior al que poseían los alumnos del Colegio de San Pablo cuando estaba regentado por los jesuitas (nota 41). También se desmentía que los Maestros tuvieran una edad provecta, pues salvo Vicente Griñó, que tenía 62 años, el resto no superaba los 43 , ni que padecieran desequilibrios mentales. Todos, según el informe, estaban «sanos y robustos», y sólo Luis Martínez había padecido «a los principios algunos dolores de cabeza nacidos de un afecto hipocondríaco». El informe entraba con mayor detalle en la defensa de la suficiencia de los docentes. En general, «en todos ellos concurren circunstancias muy recomendables» por su larga experiencia, pero se elogiaba particularmente a Vicente Griñó, Luis Martínez y Clemente Benedicto que habían sido objeto de las mayores críticas de Plana. Del primero, organista en la cer- 
cana localidad de Cuart, se decía que enseñaba latín en aquella población y que su enseñanza atraía a alumnos de lugares vecinos, incluso de la propia Valencia; Martínez había regentado varias Academias de Filosofía en la ciudad, y desde 1752 había ejercido como Maestro de Gramática por nombramiento del Cabildo eclesiástico de la Iglesia Metropolitana valenciana; Clemente Benedicto, doctor por la Universidad de Gandía, también había ejercido como profesor de Latinidad en las aulas del Cabildo catedralicio. La imagen que Plana daba del centro -calificada de «horrible pintura»- era, según el informe de la Universidad, muy distinta a la realidad. No era, desde luego, «una Casa que tiene abiertas las puertas a todo género de vicios, un lugar de abominación destinado a perder las Almas y en donde se procura borrar la idea de Dios y de su Santa Ley», sino un centro modélico. La desobediencia de Segarra a incorporar la Gramática de Mayans ordenada por el Consejo también era rechazada, pues no constaba que Segarra hubiera recibido tal orden, que sí recibió la Universidad en marzo de 1771, y que «no pudo el Claustro dar el debido cumplimiento por estar privado de las cátedras de Latinidad, Retórica y Lengua Griega por la misma ciudad» por la Concordia con los Jesuitas de 1728, causa de que todavía se impartieran en el 
ahora Seminario de Nobles. Omitía el informe que el rector Francisco Cebrián había ordenado al Seminario el uso de la Gramática mayansiana sin resultado (nota 42), pues Segarra se había inclinado por una gramática impresa en Barcelona para uso del Seminario episcopal, instalado en el edificio del ex-colegio de los jesuitas de Belén desde 1771 (nota 43).

Pero con todo, el mayor delito de Plana era el tono injurioso e irreverente de sus escritos contra personalidades tan respetables como el canónigo Segarra, el obispo Lasala, e individuos «de sobresalientes prendas» como Pérez Bayer y Vicente Blasco, a los que había calificado de «apandillados» y «secta más maligna sin comparación que la de los Jesuitas».

El fiscal del Consejo, a la vista del informe, también concluía que el denunciante había actuado «con animonia y poca veneración de unos sujetos de circunstancias tan recomendables», por lo que se había hecho acreedor a un serio castigo «que no sólo le sirva de escarmiento para abstenerse en adelante de iguales imposturas y sindicaciones menos verídicas, sí también de satisfacción a el Rdo. Obispo y demás personas agraviadas» (nota 44). 
Mayans y Plana utilizaron, como último y desesperado recurso, acudir al Presidente del Consejo y a su fiscal más influyente, Pedro Rodríguez Campomanes. Todavía Plana intentó, cerca del Conde de Aranda, en abril de 1772 desmontar el informe de la Universidad que, en su opinión, era falso y se había obtenido «a fuerza de una poderosa negociación», probablemente en relación a los primeros pasos del plan de estudios de la Universidad de Valencia que comenzó a elaborarse por entonces, y donde el Estudi General reivindicaba el regreso a su seno de los estudios de gramática, lo que lograría en 1774 (nota 45). Plana se manifestaba arrepentido por haberse expresado con excesiva aspereza contra gentes tan poderosas, pero mantenía que el estado de la enseñanza en el Seminario de Nobles era deplorable (nota 46). Mayans, por su parte, escribió a Campomanes el 28 de abril defendiendo a Plana, al que calificaba de hombre de bien y sacerdote ejemplar injustamente perseguido, y que el informe de los catedráticos Gombau y Capera iba «contra la verdad», engañando al Consejo «valiéndose para ello de medios irregulares por los quales se ha desfigurado la verdad, callando las pruevas de ellas no ignoradas de los mismos informantes i dorando la ignorancia de los maestros, sin otro motivo para ello que el que no se descubra i haga patente al Consejo la 
mala dirección del canónigo Segarra i la injusta protección de alguno que más quiere tapar las faltas de su pariente i sostener sus ocultas máquinas por medios injustos, practicados en gravísimo daño público, que ocurrir al que se causa a las letras, el que no admite restitución» (nota 47). Mayans sugería que una sóla orden del Consejo para que los Maestros del Seminario tradujeran ante un examinador adecuado simplemente un texto del castellano al latín y viceversa probaría de manera incontestable su ignorancia e incapacidad para la docencia, desmontando el informe de la Universidad.

Pese a ese último esfuerzo, el 13 de mayo el Consejo elevó su Consulta al rey calificando las denuncias de Plana como «injuriosas y denigrativas». Solicitaba que fuera separado definitivamente de la docencia y desterrado de Valencia: «...y salga de aquella ciudad ocho leguas de distancia, sin poder volver a ella hasta conseguir permiso de V.M., y que ahora ni en tiempo alguno pueda obtener Magisterio, ni otro encargo ni ocupación en aquella Universidad» (nota 48). En su resolución Carlos III endurecía todavía más el castigo, al incluir Madrid, los Sitios Reales y un radio de treinta leguas al destierro de Valencia.

La esperanza en que la expulsión de los Jesuitas supusiera una renovación en la enseñanza de las lenguas clásicas se 
había casi evaporado cuando apenas habían transcurrido cinco años del extrañamiento. El nombramiento de Moricó parecía abrir alguna esperanza a la renovación, ya que el antiguo fraile oratoriano había colaborado con Olavide en la redacción del Plan de estudios para la Universidad hispalense, interviniendo en lo concerniente a los estudios de Matemáticas y Medicina (nota 49), y había mantenido correspondencia con Mayans, elogiando su Gramática (nota 50). Pocos meses antes del nombramiento de Moricó, Mayans recibió del Consejo una orden para que informase del plan de estudios vigente en el Seminario de Nobles, y que había sido elaborado por Segarra. Su informe, fechado en marzo de 1773, como era de prever, tenía un contenido muy crítico, pues era continuista con la enseñanza practicada por los jesuitas: «este Plan nada adelanta para la mejora de los estudios. Repite lo que se practicava con poca utilidad. No propone nuevas ventajas, ni en los libros técnicos magistrales, ni en las prácticas para el adelantamiento de la lengua latina» $y$, sobre todo, mantenía la docencia separada de la Universidad (nota 51). Luego, en el comentario más pormenorizado del plan, esa acusación de continuismo quedaba muy matizada, sin que la distancia entre lo propuesto por Segarra y la propia 
concepción de Mayans resultara tan alejada como la primera observación de éste podía suponer.

Segarra proponía para la enseñanza del castellano la Introducción a la sabiduría de Juan Luis Vives, el Catecismo de Fleury y la Ortografía española de la Real Academia. Para D. Gregorio, la Intruducción a la sabiduría de Vives era un buen libro, siempre que se utilizara la traducción de Diego de Astudillo y no la de Francisco Cervantes de Salazar (nota 52); también era adecuado el Catecismo de Claude Flery, con la salvedad que fuese la traducción de Juan Interián de Ayala (nota 53), pero criticaba que la Ortografía de la lengua castellana a utilizar fuera la compuesta por la Real Academia Española, de la que existían numerosas ediciones, las últimas correspondientes a 1754, 1763 y 1770 .

Para la lengua latina, el que sólo fueran las Cartas y las Oraciones selectas de Cicerón las mencionadas le perecía a Mayans poca cosa, ya que otras obras del propio Cicerón debían ser utilizadas, y no era suficiente justificar la elección en la buena doctrina de las Cartas y las Oraciones ciceronianas, ya que el objetivo en este nivel inicial de la docencia era el mero aprendizaje del latín sin plantear cuestiones de doctrina. Para la enseñanza de la gramática castellana se proponían la compuesta por la Real Academia (nota 54), que a 
Mayans le parecía poco pedagógica y desigual, y la que por orden del obispo de Barcelona José Climent había compuesto Salvador Puig para su utilización en el Seminario diocesano (nota 55), que tampoco era del gusto de D. Gregorio.

Tampoco el desarrollo del método le parecía a Mayans adecuado: no se especificaban los ejercicios que se debían efectuar en el primer año de rudimentos, y resultaba incongruente que, en el segundo (nota 56), se pretendiera dar razones sintácticas cuando se utilizaran las Epístolas selectas de Cicerón, editadas por Pedro Simón Abril (nota 57), los Diálogos de Vives, o las Fábulas de Fedro (nota 58). En el tercer año los objetivos que el plan imponía eran, a criterio del erudito, muy ambiciosos, pues el Maestro debía enseñar a interpretar a Cornelio Nepote, César, las Cartas familiares de Cicerón y las Comedias de Terencio (nota 59). Mayans renegaba que la obra de Terencio fuera mutilada por razones de estrecha moralidad, como habían hecho los jesuitas (nota 60), y había sostenido que «la lengua latina empezó a descaecer en España desde que Terencio dejó de leerse en las Universidades» (nota 61), lo que ahora venía a reafirmar al defender que el latín debía enseñarse por autores originales y no por versiones como la que se proponía de Cornelio Schonaeus con su «Terencio Cristiano» (nota 62) que, a jui- 
cio de Mayans, nunca tuvo crédito de erudito, o por la de Marco Antonio Mureto (nota 63).

La falta de dotación para un maestro de lengua griega le parecía una carencia gravísima en un plan de estudios que «se ha mandado hacer para la mejoría de los estudios». Resultaba, en su opinión, escandaloso que se afirmara que al ser el griego lengua muerta, bastaría conocer los textos por traducciones. El conocimiento del griego era indispensable para el buen entendimiento de las Escrituras y para el conocimiento de los Santos Padres griegos, en opinión de Mayans superiores en elocuencia a los latinos. Era una prueba más que justificaba la necesidad de que las Aulas de Gramática volviera a la Universidad, donde se contaba, al menos teóricamente, con dos cátedras de lengua griega (nota 64).

Los contenidos relativos a Prosodia y Retórica eran imposibles de cumplir en la práctica. Se señalaban en el Plan la Prosodia de Juan Felipe Mey, que tenía el inconveniente de ser texto latino (nota 65), y las Instituciones Retóricas de Pedro Juan Núñez, un clásico español de la segunda mitad del siglo XVI, que Mayans consideraba magnífico (nota 66) pero de excesiva complejidad para la docencia. Pero también se indicaba que el Maestro debía enseñar a sus alumnos las fuentes principales de la oratoria -Aristóteles, Cicerón y 
Quintiliano- y utilizar el libro de Willem Hendrik Nieupoort para la mitología (nota 67), que Mayans juzgaba bueno, «aunque no para estos alumnos».

La mayor crítica de Mayans era que la enseñanza de las lenguas clásicas seguía fuera de la jurisdicción de la Universidad, y que los Maestros seleccionados por Segarra sin oposición tras la expulsión tuvieran escasísima preparación, y que la pobre calidad de la enseñanza hubiera beneficiado a los escolapios del Seminario Andresiano, cuyo rector, Benito Feliu de San Pedro, era autor de un manual publicado en 1769, de menores pretensiones que la Gramática mayansiana, que terminaría por ser adoptado en 1787 como texto por la Universidad de Valencia.

La Universidad pudo recuperar las Aulas de Gramática perdidas en 1774 (nota 68), el mismo año en que el grupo dirigido por Pérez Bayer esperaba ocupar el rectorado por mediación de su candidato Joaquín Segarra, con el apoyo circunstancial del tomismo rígido y militante del arzobispo Fabián y Fuero (nota 69). La elección en enero de 1775, por estrecho margen de doce votos contra los diez que obtuvo Segarra, del canónigo Juan Antonio Mayans, fue un breve e inesperado obstáculo para el grupo bayeriano (nota 70), pues el hermano de D. Gregorio contó con el apoyo de gentes heterogéneas a las 
que sólo unía la aversión a que el tomismo fundamentalista dominara como fuerza excluyente la enseñanza en Valencia (nota 71). En 1778, cuando Joaquín Segarra fue elegido nuevo rector, pareció que el tomismo había logrado ese control, si bien será el círculo del preceptor de los Infantes, cuya unión a los escolásticos tomistas era meramente coyuntural y sin que supusiera ninguna cesión sustancial en sus afanes hegemónicos (nota 72), quien logrará el triunfo definitivo con la llegada al rectorado de Vicente Blasco en 1784. En el tono de una carta de Mayans a Pérez Bayer, fechada a finales de diciembre de 1778, ya es perceptible la aceptación de su derrota: «Hagan lo que quieran i dégenme vivir en quietud y retiro, i más ahora que estoi desengañado del todo i que no dejarán de oponerse a mis ideas i más querrán favorecer a la ignorancia i contribuir a la perdición de la patria» (nota 73). Qué lejos quedaba aquella energía esperanzada de los meses posteriores a la expulsión de los jesuitas cuando escribía a Campomanes: «Solamente espero que suene el clarín para empezar a pelear con la barbarie» (nota 74). 
1. Domingo Moricó era valenciano y había pertenecido al Oratorio de San Felipe de Sevilla. En la capital andaluza estuvo vinculado al círculo de Olavide y a la Academia de Bellas Letras. Su nombre para Rector del Seminario de Nobles fue propuesto por el propio Canónigo Segarra, su antecesor.

2. Se refería a la Gramática del bibliotecario real Juan Iriarte, apoyada por Pérez Bayer, y dedicada a los Infantes.

3. Mayans a Martínez Pingarrón, Valencia 26 de diciembre de 1772 , en Epistolario vol. IX, Valencia 1989, p. 389.

4. Antonio Mestre Sanchis: Ilustración y reforma de la Iglesia, Valencia 1968, pp. 76-84, y SAlVAdOR AlbiñANA: «La Universitat de València i els jesuïtes. El conflicte de les aules de gramàtica (17201733)", en Studia Historia et Philologica in Honorem M. Batllori, Roma 1984, pp. 11-31.

5. Una hermana de Segarra se hallaba casada con un sobrino de Pérez Bayer, vid. Pérez Bayer a Mayans, 28 de noviembre de 1767, en Epistolario, vol. VI, Valencia 1977, p. 309.

6. Pérez Bayer, nacido en Valencia, se consideraba castellonense por haber pasado su infancia y adolescencia en Benicasim.

7. Sobre Blasco, vid. L. Esteban: «Datos para una biografía: Frey Vicente Blasco y García (1735-1813), en A. TEN (Edit.): Plan de estudios aprobado por S.M. y mandado observar en la Universidad de Valencia, Valencia 1984, pp. 11-22. En 1768 fue nombrado, por influencia de Pérez Bayer, preceptor del Infante Francisco Javier, y 
Revista de Historia Moderna

Enseñanza y vida académica en la España Moderna

muerto éste pasó a colaborar con Bayer en la educación del Infante Gabriel.

8. Mayans a Martínez Pingarrón, Oliva 6 de abril de 1767, en Epistolario, vol IX, Valencia 1989, p. 59.

9. Mayans a Campomanes, Valencia 14 de julio de 1767, en Epistolario, vol. XV, Valencia 1997, p. 444.

10. «Esta mañana me dijo Cerdá que la canongía de esa ciudad se ha dado a Segarra», en Martínez Pingarrón a Mayans, Madrid 17 de noviembre de 1767, Epistolario, vol. IX, Valencia 1989, p.104. Sobre los esfuerzos de Mayans por lograr un canonicato para su hermano Juan Antonio, véase Amparo Alemany Peiró: Juan Antonio Mayans y Siscar (1718-1801). Esplendor y crisis de la Ilustración valenciana, Valencia 1994, pp. 176-198.

11. Antonio Mestre: «Estudio preliminar» a Epistolario, vol. VI, Valencia 1977, pp. VII-LXXIX. La elección de Juan Antonio como rector se produjo en enero de 1775 frente a Joaquín Segarra, apoyado por el Arzobispo Fabián y Fuero y los miembros de la facción de Pérez Bayer, por doce votos contra diez, lo que supuso la inquina del prelado hacia las posiciones de Mayans y sus discípulos, como el canónigo Hermán. Vid. Vicente LEON NAVARRO: «Juan Bautista Hermán y Francisco Fabián y Fuero. Algunos apuntes para la comprensión de los personajes y su tiempo», en Estudis 25 (1999), pp. 183-200. Mayans no dudó en calificar a Fuero de «enemigo público de las Letras».

12. De ambas maneras calificaba Mayáns al grupo de presión dirigido por Pérez Bayer. 
13. Sobre el grupo dirigido por Pérez Bayer, vid. Antonio Mestre: «Un grupo de valencianos en la Corte de Carlos III», en El mundo intelectual de Mayans, Valencia 1978, pp. 215-240.

14. Ya el 20 de noviembre de 1767, Mayans se muestra dispuesto a dirigir los estudios en Valencia en carta a Campomanes: «Si V.S. quisiere acordarse de mi en la egecución de la reforma de las letras en esta Universidad de Valencia, seré un diligente sobrestante», para añadir más adelante: «solamente espero que suene el clarín para empezar a pelear con la barbarie», en Mayans a Campomanes, Valencia 20 de noviembre de 1767, en Epistolario, vol. XV, Valencia 1997, p. 446.

15. Mayans a Campomanes, Valencia 2 de agosto de 1768, en Epistolario, vol. XV, Valencia 1997, pp. 455-456.

16. Mayans a Campomanes, Valencia 1 de junio de 1771, en Epistolario, vol. XV, Valencia 1997, p. 521.

17. Mayans a Aranda, Valencia 11 de febrero de 1772, en Epistolario, vol. X, Valencia 1990, pp. 400-402.

18. Sobre el obispo Lasala, vid. VICENTE LeON NAVARro: «Rafael Lasala y Locela, Obispo auxiliar de Valencia. Su postura ante la extinción de los Jesuitas", en Revista de Historia Moderna, 17 (1999), pp. 353-372.

19. A.H.N. Consejos, libro 1.942, f. 271 v.

20. El 14 de mayo de 1770 el Consejo acordó que todas las Universidades de la Corona de Aragón «se arreglasen para la ins- 
trucción y enseñanza de la juventud al nuevo Arte latino compuesto por D. Gregorio Mayans», en A.H.N. Consejos, libro 1.941, ff. 160$161 \mathrm{v}$.

21. Según Plana, Segarra «está tan audaz que no contento con resistir a los repetidos Decretos del Consejo sobre la Gramática de Mayans, aún se jacta que no se dará». Vid. A.H.N. Consejos lib. 1.942 , f. 272.

22. Mayans a Aranda, Valencia 11 de febrero de 1772, en Epistolario, vol. X, Valencia 1990, p. 401.

23. Mayans a Aranda, Valencia 23 de octubre de 1770, en Epistolario, vol. X, Valencia 1990, pp. 387-388. En carta a Campomanes, cuatro días después, descalificaba a Lasala: «ni sabe latín ni conoce la erudición sino por el nombre, ni ha estudiado la buena filosofía, ni sabe fundamentalmente los dogmas de la religión ni está versado en la letura de los Santos Padres ni sabe leyes ni cánones; i con unos cortísimos principios de mathemáticas pretende ser otro Euclides», vid. Mayans a Campomanes, Valencia 27 de octubre de 1770, en Epistolario, vol. XV, Valencia 1997, p. 507.

24. A.H.N. Consejos libro 1.942, f. 275v.

25. A.H.N. Consejos libro 1.942, ff. 272-281v.

26. Segarra había ocupado la Cátedra de Filosofía Tomista en la Facultad de Artes desde 1749, para pasar a desempeñar posteriormente la de Durando hasta su nombramiento como prefecto del Colegio de Corpus Christi en 1766. Vid. Salvador AlbiÑAnA: 


\section{Notas}

Universidad e llustración. Valencia en la época de Carlos III, Valencia 1988, pp. 289 y 282.

27. Mayans consideraba que Segarra se había apoyado con los projesuitas para lograr el canonicato en perjuicio de su hermano: «en canónigo Segarra se unió con la facción social [jesuitas] para salir vencedor», en Mayans a Miguel María Nava, Valencia 6 de agosto de 1768, en Epistolario, vol. XV, Valencia 1997, pp. 456-457.

28. A.H.N. Consejos libro 1.942, f. 273v.

29. Telesforo M. HeRnANDEZ: «Enseñanza de latinidad y humanidades en la renovación pedagógica del Seminario Andresiano de Nobles (1763-1785)», en Estudis 23 (1997), pp. 269-296, y Telesforo M. HeRnandez y Vicente Leon NavarRo: «La pugna entre jesuitas y escolapios en Valencia por el control de la enseñanza secundaria (1737-1760), en Estudis 24 (1998), pp. 307-337.

30. Mas fue uno de los albaceas testamentarios de Blasco, en Salvador AlBiñana: Universidad e llustración... p. 225, not. 250.

31. A.G.S. Gracia y Justicia, legajo 674 Memorial del Dr. Joaquín Mas, Madrid 3 de octubre de 1784, y Secretario de Gracia y Justicia al Director del Seminario de Nobles de Valencia, Palacio 10 de diciembre de 1784.

32. Según Archimbaud, Director General de Temporalidades, las arcas de temporalidades de la ciudad de Valencia disponían de 171.000 rls. en noviembre de 1784. Vid. A.G.S. Gracia y Justicia, legajo 674 Juan Antonio Archimbaud a Floridablanca, Madrid 16 de noviembre de 1784. Antes de esta solución, Joaquín Mas había 
solicitado que el Seminario recuperase el capital de 14 censos que el Colegio de San Pablo de los Jesuitas poseía sobre la ciudad de Valencia por un valor de 5.608 libras y 10 sueldos, y cuyos réditos atrasados alcanzaban ya los 17.950 libras y 10 sueldos, pero esta petición fue rechazada por el Consejo.

33. En el Capítulo VI de su «Idea del nuevo método que se puede practicar en la enseñanza de las Universidades de España» de abril de 1767, dedicado a los Maestros y estudiantes de Gramática, Mayáns señalaba: «Se prohíbe que enseñe Gramática el que no haya conseguido la cátedra por oposición, habiendo precedido edictos. Esta sola prohibición excluirá a muchos, que no deben enseñar. Sean llamados a exámenes todos los maestros de Gramática actuales, para ver si son dignos de proseguir en su magisterio», en MARIANO PESET y José LUIS PESET: Gregorio Mayans y la reforma universitaria, Valencia 1975, p. 196. Esa misma idea de someter a un examen general u oposición a todo el profesorado era sostenida también por Pablo Olavide, en FrancIsco AGUILAR PIÑAL: Plan de estudios para la Universidad de Sevilla, Barcelona 1969, pp. 80-90.

34. A.H.N. Consejos libro 1.942, ff. 279-279v.

35. A.H.N. Consejos libro 1.942, ff. 277v-278.

36. A.H.N. Consejos, libro 1.942, f. 278v.

37. El texto del informe en A.H.N. Consejos libro 1.942, ff. 283289v. 


\section{Notas}

38. J. BercheZ: Arquitectura y academicismo en el siglo XVIII valenciano, Valencia 1987, pp. 72-73.

39. Según Albiñana, «Capdevila, una figura de interés escasamente estudiada, se había formado en Valencia donde estudió gramática, filosofía, medicina y matemáticas; opositó sin éxito a esta cátedra de matemáticas y a dos de medicina; subsistió como preceptor privado y con el ejercicio de la medicina por diferentes localidades, y mantuvo correspondencia con científicos europeos, entre otros con Albrecht von Haller, historiador de la medicina», en Salvador AlBIÑANA: "Cátedras y Catedráticos», en Historia de la Universidad de Valencia, Valencia 2000, Vol. II, pp. 33-56. La cita en p. 41.

40. Salvador Albiñana: Universidad e Ilustración..., p. 123. Según Mayáns, «si Vm. huviera sido cathedrático de Mathemáticas en Valencia se sabrían éstas. Ahora sólo ai balsamistas», en Mayans a Capdevila, Valencia 19 de enero de 1761, en Epistolario, vol. I, Valencia 1972, p. 216.

41. Al Colegio de San Pablo se hallaba incorporado, desde 1644, el Seminario de Nobles de San Ignacio. Es por dicha razón por la que, en ocasiones, el Colegio de San Pablo sea denominado Colegio de San Ignacio. Vid. Juan M. Fernández Soria y Ramón LÓPEZ MARTín: «Los Colegios jesuíticos valencianos: datos para su historia», en Estudis, 16 (1990), pp. 193-213.

42. «El Claustro Mayor, compuesto de un canciller, que deve ser el arzobispo de Valencia o un substituto suyo, y de los que componen dicha ciudad, i de dos canónigos i del rector de la Universidad Literaria, fue instituido con autoridad real i pontificia para hacer 
constituciones académicas absolutamente valederas. Este Claustro, pues, a quien el Consejo hizo saber su resolución para que mandasse ponerla en práctica [la Gramática] hasta ahora no ha hecho acción alguna por la qual se aya conocido que aya querido obedecer al Consejo, antes bien ha tolerado que, asistiendo en el mismo Claustro don Joaquín Segarra, uno de los dos canónigos que lo componían, se atreviesse a proferir en el mismo Claustro que, aunque a él, como director que es del Seminario de San Ignacio (sic) [San Pablo], le mandase el Consejo que ordenasse a los maestros de latinidad de dicho Seminario, que enseñassen por la mía, no obedecería», en Mayans a Aranda, Valencia 1 de mayo de 1773, en Epistolario, vol. X, p. 407-8.

43. Seguía el plan aprobado en 1770 por Jaume Matas bajo la supervisión del obispo Climent, también partícipe del grupo controlado y dirigido por Bayer. Vid. FranCESC TORT MitJANS: El Obispo de Barcelona Josep Climent i Avinent (1706-1781), Barcelona 1978, p. 176-179.

44. A.H.N. Consejos libro 1.942, ff. 289v-290.

45. Sobre el plan de estudios, remitido al Consejo en septiembre de 1772, y sólo aplicado parcial e interinamente, vid. SALVADOR ALBIÑANA: Universidad e Ilustración..., pp. 190-205.

46. A.H.N. Consejos libro 1.942, ff. 290-291.

47. Mayans a Campomanes, Valencia 28 de abril de 1772, en Epistolario, vol. XV, Valencia 1997, pp. 540-541.

48. A.H.N. Consejos libro 1.942, ff. 290v-291v. 


\section{Notas}

49. LuIS Perdices Blas: Pablo de Olavide (1725-1803), el llustrado, Madrid 1993, pp. 279-280. Moricó, tras su traslado a su Valencia natal, seguiría manteniendo su amistad con Olavide, al que defendería en 1778 en el «autillo de fe» a que fue sometido.

50. Decía Moricó a Mayans el 20 de agosto de 1768 respecto a la Gramática mayansiana: «Doy a V.S. mil enhorabuenas por ello; me las tomo yo por el gozo que me causa ver una cosa que no tiene nación alguna tan completa, siendo para todas igual el asunto...», en ANTONIO Mestre: Correspondencia de los llustrados andaluces, Sevilla 1990, pp. 368-369.

51. El informe de Mayans sobre el plan de estudios se encuentra en la B.A.H.M. del Colegio del Patriarca de Valencia, leg. 183. Agradezco al Dr. Antonio Mestre la noticia de su existencia y contenido.

52. La de Cervantes de Salazar llevaba por título Introducción y camino para la sabiduría, y contenía muchas adiciones del traductor que no eran del gusto de Mayans. La edición de la Intruductio ad sapientiam de Vives, según traducción de Diego de Astudillo, había sido efectuada por el propio Mayans en 1765 en la imprenta valenciana de Benito Monfort.

53. La traducción del mercedario Interián de Ayala del Catecismo histórico se había publicado en Madrid en 1758.

54. Gramática de la lengua castellana compuesta por la Real Academia Española, imprenta de Joaquín Ibarra, Madrid 1771.

55. Salvador PUIG: Rudimentos de la gramática castellana que por disposición del...señor D. Josef Climent, Obispo de Barcelona...se 
han de enseñar en su Colegio Episcopal y tridentino, Barcelona 1769.

56. Para Mayans debían dedicarse al latín tres años, los dos primeros de rudimentos y el tercero de sintaxis, complementado con estudios de retórica, poética y métrica.

57. Los dos libros de las Epístolas de Marco Tulio Cicerón en que se pone el uso de Cartas Narratorias i de favor, con traducción $i$ declaraciones en lengua castellana hechas por el Maestro Pedro Simón Abril, Tipografía Salvador Fauli, Valencia 1770.

58. Tanto las Epístolas de Cicerón como las Fábulas de Fedro eran utilizadas en las Aulas de Gramática jesuíticas en toda España. Vid. Bernabé Bartolomé Martínez: «Las Cátedras de Gramática de los jesuitas en las Universidades de su Provincia de Castilla», en Hispania Sacra 72 (1983), pp. 449-497.

59. Mayans había editado y prologado las Cartas selectas ciceronianas y las Comedias de Terencio con la Compañía de Libreros de Valencia, con la traducción de Pedro Simón Abril. Vid. RicARDo FRACH Y ANTONIO MESTRE: «La compañía de libreros e impresores de Valencia. Finanzas y cultura en el siglo XVIII», en Revista de Historia Moderna 4 (1984), pp. 23-46.

60. Bernabé Bartolomé: «Los Colegios de jesuitas y la educación de la juventud", en Historia de la acción educadora de la Iglesia en España, vol. I, Madrid 1995, pp. 644-682. Según los pedagogos jesuitas Terencio «mezcló el veneno con miel para que la juventud bebiese con más gusto el tósigo mortal». 


\section{Notas}

61. Gregorio Mayans: «Prólogo al libro intitulado las seis comedias de Terencio», en Obras Completas, vol. V, pp. 365-366.

62. Cornelis Schonaeus (1540-1611), al que Mayans citaba como Cornelio Schonero, publicó su Terentius christianus en Amberes en 1598. Sobre el tema del «Terencio cristiano», vid. Vicente PIcon GARCÍA: "La comedia Philavtus de Acevedo: sus deudas al «Terencio Cristiano» (Acolastvs de Gnaphevs y Samarites de Papevs), en Congreso Internacional sobre Humanismo y Renacimiento, vol. I, León 1998, pp. 599-610.

63. Se trata del francés Marc Antoine Muret (1526-1585), quien desarrolló gran parte de su labor docente en Italia.

64. Para los estudios de gramática se establecían, además de cuatro de lengua latina, una de hebreo y dos de griego, pero lo cierto es que las de griego no tuvieron titulares hasta finales de siglo. Vid. Salvador Albiñana: "Cátedras y catedráticos", en Historia de la Universidad de Valencia, Valencia 2000, vol. II, pp. 33-56.

65. Juan Felipe Mey: Prosodia, imprenta de Benito Monfort, Valencia 1764.

66. Pedro Juan Nuñez y Antonio de Lebrija eran considerados por Mayans los dos mayores retóricos que había tenido España.

67. Nieupoort (1670-1730) publicó Rituum qui olim apud romanos obtinuerunt, Venecia 1749.

68. Pablo Perez Garcia: «Las aulas de gramática», en Historia de la Universidad de Valencia, Vol. II, Valencia 2000, pp. 173-186. 
69. Fabián y Fuero se hallaba vinculado a Pérez Bayer desde que ambos fueron canónigos de Toledo.

70. Sobre la génesis de las facciones universitarias en Valencia y la unión de Pérez Bayer con los tomistas, vid. Antonio Mestre SANCHIS: «Pugnas por el control de la Universidad después de la expulsión de los jesuitas», en Revista de Historia Moderna 8-9 (1988-1990), pp. 91-118.

71. Para Albiñana, «1774 constituye uno de los puntos culminantes del enfrentamiento escolástico y del hegemonismo tomista. Esta es la situación que heredará Maynas y que paradójicamente posibilita su acceso al rectorado. Juan Antonio Mayans era, en esos momentos, el único rector posible». Vid. SALVADOR AlBIÑANA: «Los conflictos escolásticos y el rectorado de Juan Antonio Mayans en la Universidad de Valencia», en Mayans y la llustración, Valencia 1981, Tomo II, pp. 411-428, cita en p. 417.

72. El baluarte del tomismo más exluyente, el Arzobispo Fabián y Fuero, será contrario al Plan del rector Blasco de 1786. Vid. MARIANO Peset y José LuIS PeSET: «Reforma de los estudios», en Historia de la Universidad de Valencia, Valencia 2000, vol. II, pp. 65-84.

73. Mayans a Pérez Bayer, Valencia 26 de diciembre de 1778, en Epistolario, vol. VI, p. 373.

74. Mayans a Campomanes, Valencia 20 de noviembre de 1767, en Epistolario, vol. XV, Valencia 1997, p. 446. 